\title{
RETRACTED ARTICLE: Experimental Determination of Effects of Impact Inducing Characteristics of Natural Hailstones
}

M.E. Uz ${ }^{1,2}$ (D) $\cdot$ Y. Yaldiz ${ }^{3}$

Received: 21 May 2018 / Accepted: 12 May 2019 / Published online: 16 August 2019

(C) The Society for Experimental Mechanics, Inc 2019

\section{Retraction Note:}

The authors have retracted this article [1] because it reports research findings from an unpublished Master's thesis by Yufei $\mathrm{Wu}$ in Figures 7-10 and Tables 4, 5 and 7 without proper attribution or permission. All authors agree to this retraction. The online version of this article contains the full text of the retracted article as electronic supplementary material.

[1] Uz, M., Yaldiz, Y. Experimental Determination of Effects of Impact Inducing Characteristics of Natural Hailstones. Exp Tech (2019). https://doi.org/10.1007/s40799-019-00326-y

Electronic supplementary material The online version of this article (https://doi.org/10.1007/s40799-019-00326-y) contains supplementary material, which is available to authorized users.

M.E. Uz

mehmet.uz@adu.edu.tr

1 Department of Civil Engineering, Faculty of Engineering, Adnan Menderes University, 09100 Aydin, Turkey

2 School of Civil, Mining and Environmental Engineering, University of Wollongong, Wollongong, NSW 2500, Australia

3 Faculty of Engineering, University of Adnan Menderes, 09100 Aydin, Turkey 